drawn from the vein for a more careful study by the accurate Van Slyke method ${ }^{11}$ for determining the carbon dioxid of the plasma.

TREATMENT OF OTHER COMPLICATIONS

Nephritis. - In acidosis cases, slight amounts of albumin and hyaline casts are frequently found in the urine. After the patient becomes sugar free, this condition usually improves. Actual nephritis is not uncommon. In such cases, fasting should be avoided, and the urine should be rendered sugar free by moderate reduction of the carbohydrate and the total calories. Only in uremic cases or in cases in which a blood urea determination proves nitrogen retention to be present should the protein of the diet be unduly curtailed. Nephritis is no contraindication to dietetic diabetic treatment, and improvement of both conditions is the rule with judicious management. Edema of nonnephritic origin is common in diabetic patients on low diets containing much salt. It may also be caused by the taking of large amounts of soda. Limitation of salt, omission of sodium bicarbonate, and sometimes restriction of the liquid intake relieve this condition.

Skin.-Great caution to avoid even the tiniest break in the contiguity of the skin is necessary. Daily bathing and the liberal use of talcum powder are indicated.

Pruritis Vulvae.-This usually clears up as soon as the urine is sugar free, if it is not dependent on some local cause.

Furuncles.-These are frequent in diabetes. The old warning to examine the urine in every case of boils is still sometimes neglected. Aside from surgery, furuncles may be treated locally by a 3 to 5 per cent. ammoniated mercury ointment with white petrolatum. A daily bath should be ordered, followed by a boric acid sponge over the entire body, to prevent extension of the infection.

Diabetic Gangrene. - This condition is the endresult of an occlusive angiitis. Prodromal symptoms include numbness and chilliness of the extremities, and intermitent pains lasting frequently for years. In this condition hot foot-baths, massage, short walks and elevation of the feet while at rest should be prescribed. Moist, hot compresses applied for brief intervals once or twice daily are helpful in relieving pain. The use of salicylates may lead to the appearance of a positive ferric chlorid reaction in the urine, when no acidosis is actually present. If actual gangrene develops, a surgeon should be called at once.

Sepsis.--It is sometimes difficult as well as injudicious to free a septic patient of sugar. Restricted diets may be badly borne. Supportive and stimulative measures may be required until improvement permits stricter treatment.

Pregnancy and Diabetes.-A small amount of glucose is not uncommonly found in the urine of pregnant women. In such cases the carbohydrate should be limited and special care be generally employed. Marked clinical symptoms of diabetes had best be regarded by the general practitioner as an indication for an early abortion, though in expert hands cases are now carried through successfully to confinement.

\section{DIABETES IN CHILDREN}

Children are especially liable to acidosis. One should be careful never to permit an unlimited amount of fat in the diet, and to restrict fatty foods during the minor illnesses to which children are susceptible.

11. Van Slyke, D. D.: Jour. Biol. Chem., 1917, 30, 289.
It should be remembered, however, that on account of growth about double the amount of food required by adults must be given to children. Happily, the life of diabetic children is becoming increasingly prolonged under modern treatment. One of my little patients has completed her eighth year, diabetes beginning at 5 .

33 East Sixty-Third Street.

\section{END-RESULTS IN THE PROSTATECTO- MIZED PATIENT: A COMPARA- TIVE ANALYSIS}

BASED ON ONE HUNDRED AND TEN CASES (FIFTY-FIVE SUPRAPUBIC, FIFTY-FIVE PERINEAL)*

CLARENCE MARTIN, M.D.

Captain, M. R. C., U. S. Army; Visiting Genito-Urinary Surgeon, St. Louis City Hospital

ST. LOUIS

My natural interest, as a urologist, in the life of the prostatectomized patient after complete operative convalescence, particularly as it involved the several important functions subjected to surgical assault, prompted me, in 1917, to write to a considerable number of general practitioners for information of those of their patients on whom a prostatectomy had been done. I enclosed a printed questionnaire covering the following points:

When was operation performed?

Age of patient at operation.

Suprapubic or perineal?

Did wound heal promptly?

If urinary fistula resulted, how long was it in healing?

Present frequency of urination: (1) day; (2) night.

Has patient full control of bladder?

Has patient incontinence? Complete or partial?

Cystitis?

Pain: Connected with Urination? Independent of Urina-

tion? Location.

Amount of residual urine.

What force to stream?

Effect of operation on sexual power.

Increased, lessened or unchanged?

Was there stricture of urethra following operation?

Is urine clear?

Has there been stone formation since operation?

Effect of operation on patient's general health.

I chose the family physician as the source of my information because I believed he would be in closer touch with prostatectomized patients than the genitourinary surgeon. When we have done the prostatectomy and returned the patient to his physician, we usually lose sight of him; but the continued and more intimate relationship between family physician and patient permits the general practitioner to pass accurate and unbiased judgment on the end-results of surgical procedures. Hence, I feel sure that the figures I am about to present represent more reliable conclusions than if they were based on the reports of the men doing the work. Fully to know a person, one must "summer and winter" with him. The family physician does this with his patients. The specialist does not.

The employment of a printed questionnaire secured uniformity of information.

* Read before the St. Louis Medical Society, March 9, 1918 
COMPARISON OF THE TWO OPERATIVE PROCEDURES

Curiously enough, on the final balancing of my returns, I found that I had reports on fifty-five cases of suprapubic prostatectomy, and fifty-five in which the perineal operation had been performed. I was not so much struck by this exact balance of choice of cerative procedure as $I$ was by the fact that the perineal operation was still in large vogue. While it is true that in recent years the suprapubic operation has attracted by far the wider attention in the literature of prostatectomy, yet by glancing at the accompanying chronological chart, we may readily see that there is not the numerical disproportion between the two operations which most of us held to be the case. Even as late as 1916, as shown by the chart, the perineal was two thirds as popular as the suprapubic operation.

The fairness of the conclusions reached after a comparative analysis of these 110 cases becomes all the more obvious when one remembers the even balance of cperative routes.

Some of the patients were operated on by myself. others by other urologists, general surgeons, general practitioners and gynecologists. Hence they represent a wide assortment of surgical talent.

As far as the age factor is involved, it is interesting to note that those subjected to the suprapubic operation were, on an average, a trifle more than two years older than those subjected to the perineal. The average age of the suprapubic patients was 66.5 years, and that of the perineal patients, 64.3 years.

It is true that hitherto the perineal route has had a smaller operative mortality than the suprapubic; but during the past few

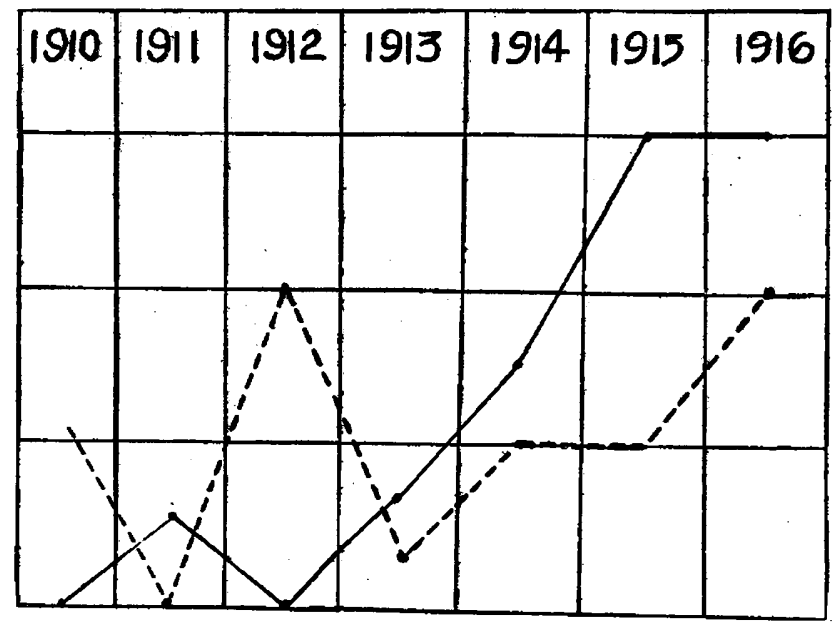

Comparative popularity of the two operations: solid line, suprapubic; broken line, perineal.
Entering on the matter of immediate operative convalescence, we may generously grant that any prostatectomy wound that closes entirely within four weeks may be designated as having healed promptly. As shown in Table 1, 61.2 per cent. of the suprapubic cases

TABLE 1.-CLOSURE OF WOUND

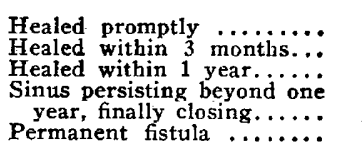

\begin{tabular}{ccrc} 
No. & Puprapubie & & \multicolumn{2}{c}{ Perineal- } & Pert. & No. & Per Cent. \\
30 & 61.2 & 21 & 42 \\
16 & 93.8 & 12 & 66 \\
3 & 100. & 9 & 84 \\
0 & 0. & 5 & 10 \\
0 & 0. & 3 & 6
\end{tabular}

in this series healed promptly as against 42 per cent. of the perineal cases. Of the suprapubic cases, 93.8 per cent. were healed within three months, while only 66 per cent. of the perineal cases closed up in the same period. Within one year following operation, the wounds in a full hundred per cent. of the suprapubic cases were entirely healed; of the perineal wounds, only 84 per cent. were healed by the end of the year. In other words, while every suprapubic wound had healed within a year, 16 per cent. of the perineal wounds were still discharging urine through a sinus. Carrying the analysis further, we find that in 6 per cent. of the cases of the entire perineal series, a permanent discharging sinus persisted. One of these cases presented a vesicorectal fistula, with the urine discharging into the rectum.

\section{DIVERGENCE IN END- RESULTS}

It is at this point that the end-results of the two modes of prostatectomy begin their wide divergence. Since these endresults are expressed in mathematical terms, they years the mortality figures of the two operations have been rapidly approaching each other, particularly since the two-step suprapubic operation has been popularized. In view of this reduction of suprapubic. mortality, largely due to better control of the renal factor, the element of extra hazard does not participate so markedly as formerly in the choice of operative procedure. Furthermore, since the probable end-results of an operative procedure are a weighty factor in the determination of its feasibility and choice, it is obvious that even though there is a slight extra operative hazard, either actual or apparent, this is, in a very large degree, neutralized by superior end-results. After all, the end-result of an operative measure is the acid test of its applicability.

At this point, I wish to state that any apparent discrepancy between the mathematical determination of any single factor and the total number of cases is due to the fact that in some instances certain questions were unanswered. Illustrative percentages of the several items involved are based on the actual number of available answers to each individual question. Again, when answers were vague or obviously incorrect, they were not used in the estimation of findings. are the more readily grasped, and the element of personal bias is eliminated.

In the vast majority of cases of prostatic hypertrophy, the symptom forcing the patient to seek surgical aid is either intolerable frequency of urination, particularly at night, or retention. Of necessity, removal of the gland relieves the retention. Now let us examine the figures and see what degree of relief is secured from the inordinate frequency. While, of course, no sharply defined line between normal and abnormal frequency can be drawn, yet for the purpose of conveniently arriving at an approximate standard of normality, we may arbitrarily fix a three-hour period for the day and a four-hour period for the night.

From my questionnaire I received definite information on the day urination of thirty-seven suprapubic and of thirty-six perineal patients. The results are summarized in Table 2 . Of the thirty-seven suprapubics, thirty urinate during the day at normal intervals, five every two hours, one every hour, and one every thirty minutes. In the thirty-six perineal cases, twenty-four of the patients were restored to normal diurnal frequency, ten can hold the urine only two 
hours and two must urinate every hour. There are no perineal cases in the thirty-minute class.

Expressing these results in percentages, we find, among the suprapubic cases, that they are good in 81, fair in 13.5 and poor in 5.4 per cent., while among the perineal cases the day results are good in 66.6 , fair in 27.7 and poor in 5.5 per cent.

As we usually determine nocturnal frequency by the number of times a patient is compelled to arise from bed, I have thought it simpler to classify the night frequency in this manner, rather than to express it in periods of hours.

I have information on the nocturnal frequency of thirty-five suprapubic and thirty-eight perineal patients. At this point the parallel figures are quite impressive. Of the patients in the suprapubic cases, thirteen do not arise at night at all, sixteen only once or twice, two three times, and four oftener than three times.

On the other hand, in the perineal cases, only one patient passes the night without urinating; sixteen arise once or twice; nine three times, and twelve must get up oftener than three times. Thus we may say that of the thirty-five suprapubic cases, twenty-nine have a normal nocturnal frequency, whereas only seventeen of the thirty-eight perineal cases are as fortunate. The patients in nine of the perineal cases

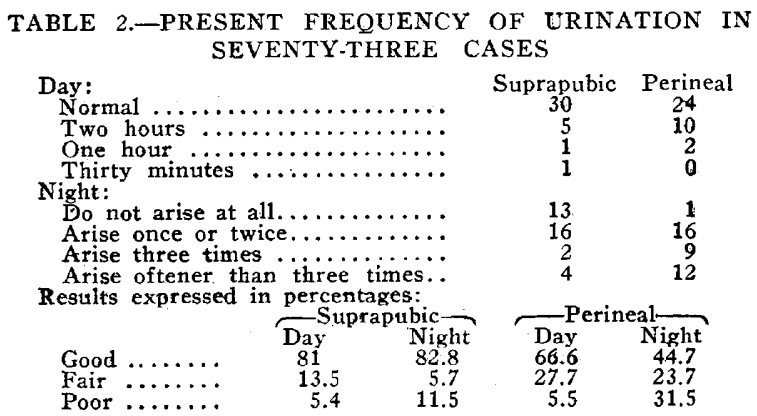

arise three times and in twelve oftener than three times.

Since the correction of marked frequency, and especially nocturnal frequency, is an important purpose of prostatectomy, the gross figures and percentages covering this function form an index of no light value in prosecuting a comparative analysis of the two operations. My percentages demonstrate that, so far as day frequency is concerned, the suprapubic has a big lead over the perineal route, and a comparison of the night results shows that in suprapubic cases these results are almost twice as gratifying as in the perineal cases. While 82.8 per cent. of the suprapubic patients were restored to a very comfortable degree of night frequency, only 44.7 per cent. of the perineal patients were as fortunate, and whereas the night results in the suprapubic cases are poor in 11.4 per cent., among the perineal cases 31.5 per cent. may be so designated. In other words, the poor results of the perineal operation, as far as they relate to the important item of nocturnal frequency, are nearly three times as great as in the suprapubic series.

When we bear in mind the almost intolerable suffering that is consequent on an incontinent bladder, efforts to preserve the integrity of its function seem easily entitled to the most urgent consideration. The patient who returns home after a prostatectomy with a hopelessly incontinent bladder is not likely to hold his operation a success, even though it did effect the removal of his prostate gland.
Concerning this phase of our subject, I have definite information of forty-six suprapubic and fifty perineal cases, which is summarized in Table 3 . Of the fortysix suprapubic patients, thirty-seven have full control of the bladder function, seven have partial control, and two have complete incontinence. Of the fifty perineal patients, thirty-two have futl control, eleven have par-

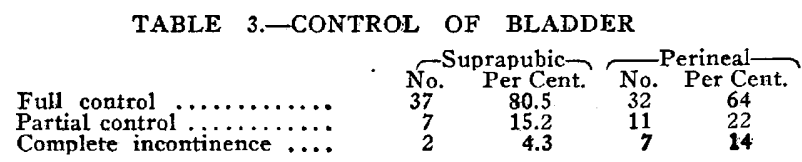

tial control and seven have complete incontinence. Expressed in percentages, these results loom up still more strikingly. While the patients in 80.5 per cent. of the suprapubic cases have full control, only 64 per cent. of the patients in the perineal cases are equally lucky. Of the suprapubic cases, 15.2 per cent. are put into the partial control designation, while 22 per cent. of the perineal cases must be so described.

The suprapubic patients with complete incontinence embrace 4.3 per cent. of the entire suprapubic series, while 14 per cent. of the perineal cases are in this pitiable state.

In the examination of the various elements entering into the comfort of the prostatic postoperative life, only in the elements of persisting cystitis and pain do we find a balance in favor of the perineal route. By the figures set forth in Table 4, the questionnaire shows that 35 per cent. of the suprapubic patients complain of cystitis of varying grades, and 21 per cent. refer to definite pain at some point in the region of the site of operation. Of the perineal patients, 31 per cent. have, cystitis and only 16 per cent. pain.

The answers relating to residual urine are too vague and inconclusive to be of substantial worth. Hence this factor will not be discussed.

As far as the force of the urinary stream is concerned, the figures so materially favor the suprapubic operation that I am sure the factor of urethral stricture must enter more deeply into the question of relative merit than we have hitherto thought. Of course, in working out the causes of reduced force of the stream, we must not forget the expulsive power of the bladder itself. I believe that in many instances the tonicity of the bladder is greatly improved on removal of the obstructing prostate; but if a stricture follows operation, this tonicity cannot be restored.

Of forty-two suprapubic cases investigated, twentytwo have a stream of good force, in eight the stream is

TABLE 4.-INCIDENCE OF CYSTITIS AND PAIN

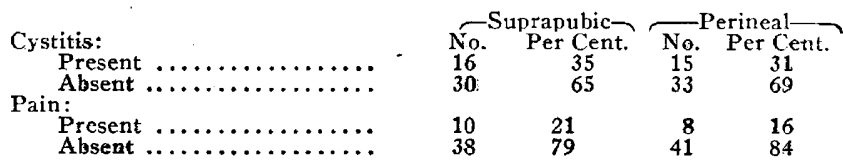

fair, in twelve it is poor. In only twelve out of fortysix perineal cases is it good; in seventeen it is fair, and in seventeen poor. The percentage figures, as given in Table 5, show these results more graphically.

This suspicion of a preponderance of urethral damage following perineal prostatectomy becomes alt the more clearly warranted when we examine the actual stricture reports. Among forty-six suprapubic cases there are three definite reports of stricture. Among forty-three perineal cases there are ten such 
reports. Expressed in percentages, these results are: suprapubic 6.5 per cent., perineal 23.2 per cent.

As the possibility of stricture formation is a most important element in the remote success of a prostatectomy, it is well to give this point the consideration its importance warrants.

Regarding the clarifying effect prostatectomy has on the urine, the two operative modes enjoy somewhat similar percentages, which are presented in Table 6.

However close in agreement the figures on the turbidity of the urine may be, we find in the percentages

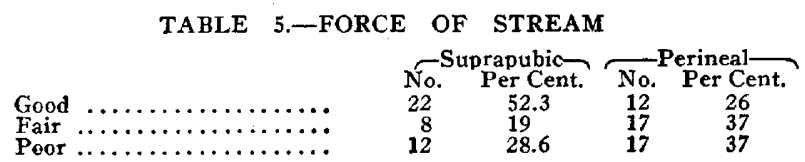

of stone formation a feature of considerable interest. Following suprapubic prostatectomy there was no stone formation in our series, while stone was formed in 4.1 per cent. of the perineal cases. Since lithiasis is favored through incomplete or difficult emptying of the bladder, with consequent urinary stagnation, we may look on stone formation as bearing a very close relationship to the factor of stricture formation.

While with the majority of these old men, active sexual life has ceased to be a matter of grave concern, yet there are many who, discussing with me the immediate and remote dangers of prostatectomy, inquire

TABLE 6.-CHARACTER OF URINE

\begin{tabular}{|c|c|c|c|c|}
\hline & No & prapubic- & $\mathrm{No}^{\mathrm{I}}$ & $\begin{array}{l}\text { Perineal- } \\
\text { Per Cent. }\end{array}$ \\
\hline $\begin{array}{l}\text { Clear } \\
\text { Turbid } \ldots \ldots \ldots \ldots \ldots \ldots \ldots \ldots \\
\text { Variable } \ldots \ldots \ldots \ldots \ldots \ldots \ldots\end{array}$ & $\begin{array}{r}30 \\
14 \\
2\end{array}$ & $\begin{array}{r}65.2 \\
30.4 \\
4.4\end{array}$ & $\begin{array}{r}31 \\
14 \\
1\end{array}$ & $\begin{array}{r}67.4 \\
30.4 \\
2.1\end{array}$ \\
\hline
\end{tabular}

seriously into the possibility of damaged sexual function. Hence the figures covering this phase are not without instructive value.

On this postoperative phase I have information touching on thirty-three suprapubic and thirty-three perineal cases, a similarity that makes the figures given in Table 7 easier of comparative understanding. In twenty-one of the suprapubic cases there was no change effected in the sexual function, in nine it was diminished and in three increased. In the perineal series this function was unchanged in sixteen cases, diminjshed in sixteen, and increased in only one. Here it

TABLE 7.-EFFECT ON SEXUAL POWER

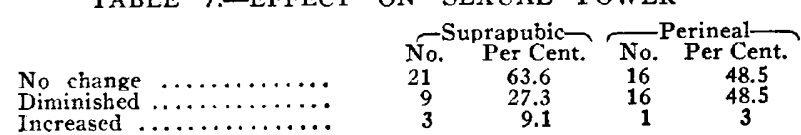

should be remembered that the patients in the suprapubic cases are, on an average, two years older than those in perineal cases.

Naturally the effect of prostatectomy on the general well-being of the patient is of the utmost importance, and the figures describing this item should be carefully digested. Among forty-three of the patients in fortynine suprapubic cases, the effect on the general health was good, in three it was bad, and in three patients there was no change. In thirty-six of the forty-seven perineal cases the effect was good, and in four it was bad, with no change in seven. A glance at Table 8 shows that in this important feature of prostatectomy, the suprapubic operation has a big lead over the perineal.

\section{CONCLUSION}

It is well that the perineal operation is losing popularity, for in this careful analysis of results, only in three inconsequential features is an advantage to be found for this route in the parallel figures. In all the

TABLE 8--EFFECT ON GENERAL HEALTH

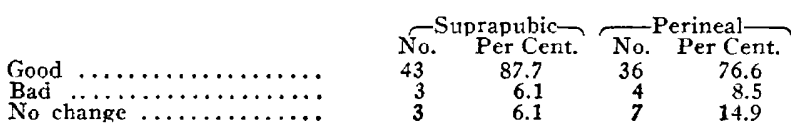

important features the suprapubic operation has a big lead, showing beyond the shadow of a doubt that, measured in end-results, suprapubic prostatectomy is vastly superior to the perineal operation.

3700 Von Versen Avenue.

\section{GLOBULES OF METALLIC MERCURY IN THE TISSUES}

\author{
FINDINGS IN AN AORTIC ANEURYSM WITH \\ EROSION OF THE VERTEBRAE * \\ JOHN A. KOLMER, M.D. \\ AND \\ E. V. MASTIN, M.D. \\ PHILADELPHIA
}

The case here reported is one of considerable interest in view of the finding at necropsy of numerous globules of metallic mercury in the tissues of an aneurysm of the aorta, and the eroded vertebrae of the spinal column. Myriads of minute globules of mercury were scattered throughout these tissues, the metal being easily expressed and collected into larger globules in the concavity of the aneurysm and eroded tissues.

The deposition of the metal in the actively eroding and necrotic tissues, and probably primarily in the necrotic vertebrae, constitutes a finding of unique interest and considerable importance, although by no means rare or unusual. As early as 1579 , Fernel ${ }^{1}$ states, in his work on the venereal disease, that metallic mercury may be found in the "putrid caries of bones" if the patient has been exposed to the vapor of mercury or of cinnabar, and also in those who have had repeated rubbings with the ointment. Since then, several observers have recorded the presence of metallic mercury in the necrotic bones of syphilitics receiving vigorous mercurial treatment; the literature of the last twenty-five years, however, contains but few records, owing probably to the practice of less vigorous dosage with mercury in the treatment of syphilis.

That mercury may be found by chemical methods in the brain, liver and other internal organs following its administration by inunction, subcutaneous and intramuscular injections of soluble and insoluble salts, or by swallowing, is well established; Fernel believed that the mercury as such was transported to these organs, but this result is now regarded, according to Hallopeau, as due to successive combinations (as mercury albuminate) and decompositions, ending by the formation of a soluble salt and pure metal, or a reducible insoluble salt. The method of administra-

- From the Laboratories of the Philadelphia Polyclinic

1. Fernel d'Amiens, J.: Le meilleur traitement du mal vénérien, 1579; traduction, preface et notes par L. Le Pilier, Paris, 1879.

2. Hállopeau, H.: Du mercure; action physiologique et thérapeutique, Paris, 1878. 